Trinity University

Digital Commons @ Trinity

Health Care Administration Faculty Research

Health Care Administration

$2-2000$

\title{
The Production of Health and the Valuation of Medical Inputs in Wage-Amenity Models
}

Edward J. Schumacher

TrinityUniversity, eschumac@trinity.edu

John C. Whitehead

Follow this and additional works at: https://digitalcommons.trinity.edu/hca_faculty

Part of the Medicine and Health Sciences Commons

\section{Repository Citation}

Schumacher, E.J. \& Whitehead, J.C. (2000). The production of health and the valuation of medical inputs in wage-amenity models. Social Science and Medicine, 50(4), 507-515. doi: 10.1016/S0277-9536(99)00296-8

This Article is brought to you for free and open access by the Health Care Administration at Digital Commons @ Trinity. It has been accepted for inclusion in Health Care Administration Faculty Research by an authorized administrator of Digital Commons @ Trinity. For more information, please contact jcostanz@trinity.edu. 


\title{
The production of health and the valuation of medical inputs in wage-amenity models
}

\author{
Edward J. Schumacher*, John C. Whitehead ${ }^{1}$ \\ Department of Economics, East Carolina University, Brewster Building, Greenville, NC 27858-4353, USA
}

\begin{abstract}
Using a hedonic wage-amenity model, this paper examines the valuation of medical inputs into the production of health. The data used in this study include the incomes, demographics and measures of human capital for households in eastern North Carolina with county level medical input supply. These data allow an estimate of the marginal value of medical care inputs such as the physician to population ratio and the availability of specialized services in an area of the country where the lack of available medical care has been of particular concern to policy makers. Our results indicate that while health care inputs are not a significant determinant of earnings overall, they are important in counties that have been designated as medically underserved. In underserved counties each additional physician per 10,000 individuals in the county decreases earnings by about $11.6 \%$. This suggests that physicians act as an amenity and workers are willing to accept lower wages to locate in counties with a higher physician to population ratio. C) 2000 Elsevier Science Ltd. All rights reserved.
\end{abstract}

Keywords: Hedonic; Amenity; Health production; Medical inputs

\section{Introduction}

The assumption underlying the hedonic wage model is that workers prefer jobs with more pleasant working conditions. The greater supply of workers for pleasant jobs will lower the wage in these jobs and, in equilibrium, the difference in wages between two jobs will reflect the workers' marginal valuation of the difference in working conditions. Firms have different isoprofit

\footnotetext{
A previous version of this paper was presented at the 1996 Southern Economic Association Meetings in Washington, DC.

* Corresponding author. Tel.: +1-252-328-1083; fax: +1252-328-6743.

E-mail addresses: $\quad$ schumachere@mail.ecu.edu (E.J. Schumacher),whiteheadj@mail.ecu.edu (J.C. Whitehead)

${ }^{1}$ Tel.: + 1-252-328-6821; fax: + 1-252-328-6743
}

curves and thus their willingness to provide pleasant or productivity enhancing job characteristics will vary. Similarly, different workers have different preferences and there is a non-random sorting of workers and firms. If working conditions are uncorrelated with productivities, firms with a low cost of producing pleasant conditions will tend to be matched with workers with a stronger preference for these conditions, while firms with a high cost of producing pleasant conditions will tend to attract workers with a lower preference for these characteristics. Thus, since the resulting hedonic wage function is an envelope of isoprofit and iso-utility curves the resulting compensating differential reflects the preferences of the marginal worker and the marginal effect on firm profit.

One practical application of this model is the valuation of the environmental and social amenities that vary across regions. This paper examines the valuation 
of inputs into the production of health. Inputs into health production, such as environmental health amenities and the availability of medical care services, will tend to attract workers and firms, due to the enhancement of labor productivity and the amenity value to consumers and either increase or decrease wages, depending on the relative size of the two effects. If the value of the marginal product of the amenity is greater than the willingness to pay for the amenity, then wages will rise; and vice versa.

Hospital services, nursing home services and other medical services are quasi-public goods. Non-profit health care enterprises may arise where a sufficient minority of voters is dissatisfied with the market's and government's level of provision (Weisbrod, 1975, 1988). High quality hospitals and doctors may also enhance a community's sense of pride and well being. They may indirectly provide benefits to local business by improving labor productivity. In addition, excess hospital capacity provides insurance for the currently healthy citizens in that a bed will be available should they need one. Thus, while these components of the benefits of medical care are likely to be rather significant, it is not likely that their economic value will be fully reflected in market prices.

To the extent that managed care has de-emphasized the use of physicians and hospitals and tends to use more nurse practitioners and physician assistants the public good component of medical care may have diminished. In addition, physicians serve rural areas by doing rotations into outlying areas rather than living in them and better roads, helicopter ambulances and telemedicine all tend to reduce the value of physicians and hospitals which are located in the local county. The implication is that while traditional medical inputs may still be important, their contribution is not as great as they were prior to the rise of managed care and the reduced transportation costs. Thus, the results found in this paper using data from the early 1990s are likely to find a smaller impact of medical care inputs than a study using older data. We test for these changing effects below by splitting our data into two time periods and examining differences.

There have been relatively few hedonic wage studies that considered health amenities. Blomquist et al. (1988) estimate housing and wage hedonic equations in the context of an urban quality of life study and find that health-related environmental disamenities, such as Superfund sites, are capitalized in both land and labor markets. Clark and Kahn (1989), in the context of a recreational fishing valuation study, find that, holding

\footnotetext{
${ }^{2}$ The use of 'underserved' here refers to a need-based shortage as defined by Lee and Jones (1993) and not necessarily an economic shortage.
}

constant housing prices, the number of physicians in an urban area has no effect on wages. Gyourko and Tracy (1991) find that the number of hospital beds is a valued publicly provided good in the wage equation but does not affect the housing price. These studies use national, urban data.

This paper differs from previous research in two important ways. First, our data contain a broader range of medical inputs than utilized in previous research that may be considered as local amenities and those that increase worker productivity. This will allow us to examine the effects of omitting these variables. Also, we focus on a particular problem with medical care access: access to medical care in an underserved, rural area (Goetz and Debertin, 1996) ${ }^{2}$. The data used in this study include the incomes, demographics and measures of human capital for over 3000 households in eastern North Carolina with county level medical care inputs. Using a hedonic wage model, these data allow an estimate of the marginal value of medical care inputs such as the physician to population ratio, number and size of hospitals and the availability of specialized services in an area of the country where the lack of available health care has been of particular concern to policy makers.

The paper proceeds as follows. The next section lays out the theory behind the hedonic wage model. We then describe the data used in the paper and present descriptive statistics. The fourth section presents our results and conclusions follow in the final section.

\section{Theory}

Our modeling approach begins with utility and health production functions, which are then integrated into a hedonic model of wages and rents. We assume individuals possess a utility function of the following form:

$u=u(X, H, S)$

where $u($.$) is the utility function, X$ is a vector of market goods, $H$ is the housing commodity and $S$ is individual health status, measured as annual sick days. Utility is increasing in the composite commodity, the housing commodity and decreasing in sick days. Sick days decrease utility by decreasing the number of days spent engaged in utility producing activities.

Individual health status is endogenous and can be produced according to the health production function:

$$
S=s(Q, M)
$$

where $Q$ is a vector of medical care inputs priced in markets, $S_{\mathrm{Q}}<0$ and $M$ is a vector of unpriced medical care inputs, $S_{\mathrm{M}}<0$. In addition to the public good 


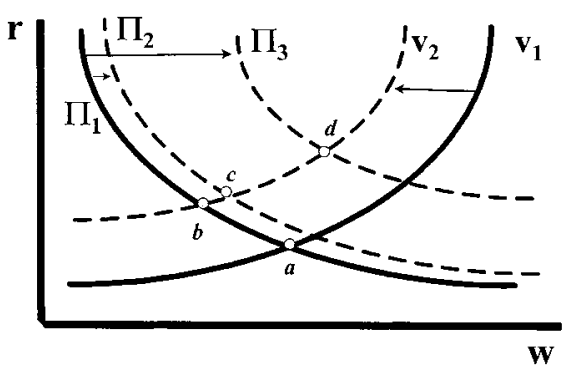

Fig. 1. The determination of wages and rents.

nature of medical care mentioned above, a significant portion of the full cost of medical care inputs, especially in underserved rural areas, is the unpriced opportunity cost of travel time for access to medical care. In this respect, access to medical care inputs is a quasi-public good. The full costs of medical care inputs are inversely related with access.

We integrate the health production function into a hedonic model, which is based on the models of Blomquist et al. (1988), Clark and Kahn (1989) and Gyourko and Tracy (1991). These models are based on the hedonic price models of Rosen (1974) and Roback (1982). After substitution of (2) into (1), households are assumed to possess indirect utility functions $v($.$) of$ the form

$$
\begin{aligned}
v(r, w, M) & =\max u(X, H, s(Q, M)) \\
\text { s.t.w } & =P_{X} X+P_{Q} Q+r H+h S
\end{aligned}
$$

where $w$ is annual income, $P_{i}$ are vectors of market prices, $i=X, Q$ and $h$ is the opportunity cost of sick days. Indirect utility is decreasing in the land rent, increasing in income and medical inputs. Market prices are assumed constant and suppressed for simplicity.

Business firms are assumed to possess production functions of the form

$X=X(L-S, H)$

where $X($.$) is the production function, L-S$ is the labor input net sick days and $H$ is the land input. The capital input is suppressed for simplicity. Output is increasing in the inputs. After substitution of (2) into (4), business firms are assumed to possess indirect profit functions of the form

$\Pi(r, w, M)=\max P_{X} X(L-s(Q, M), H)-w L-r H$

where $\Pi($.$) is the indirect profit function which is$

\footnotetext{
${ }^{3}$ For an empirical example of the overall positive effect of amenities on wages in the context of public infrastructure and wages, see Dalenberg and Partridge (1997).
}

decreasing in $\mathrm{r}$ and $\mathrm{w}$. Medical care inputs have a positive effect on profit by increasing the productivity of the labor input. The output price, $P_{X}$, is assumed constant and suppressed in the indirect profit function for simplicity.

The unpriced medical care inputs can become capitalized in both land and labor markets. To see this, consider the graphical model in Fig. 1 of the indifference and isoprofit curves in $r, w$ space. With mobility in the long run, household utility and firm profits will be equalized across locations. Incomes and rents will be determined in the markets after sorting among workers and firms take place. The initial equilibrium, point $a$, summarizes these prices. Improvements in medical care inputs has a positive direct effect on rents and a negative direct effect on wages as workers enjoy higher utility levels, $v_{2}>v_{1}$ and move to the counties with these characteristics, equilibrium $b$. Profits for business firms are also greater in the attractive locations; so, as firms move to these areas land rents increase further. Depending on the size of the productivity effect on firm profits, wages may be negatively (equilibrium $c$ ) or positively (equilibrium $d$ ), affected by firm location decisions ${ }^{3}$.

Solving the indirect utility function, Eq. (3) and indirect profit function, Eq. (5), for $r$ and $w$, equating these functions and solving for equilibrium wage and land rents, respectively, yields reduced form wage and rent equations in which these prices depend entirely on medical care inputs $w^{\prime}=\mathrm{w}(\mathrm{M}), r^{\prime}=\mathrm{r}(\mathrm{M})$ where $w^{\prime}$ and $r^{\prime}$ are the equilibrium prices for homogeneous households.

\section{Empirical specification}

Our data contain no information on household specific land rents or housing prices in which to measure the hedonic price function. Therefore, we assume that the equilibrium wage function includes a measure of land rent in order to hold the effect of housing markets on wages constant across locations. The empirical specification of our model is

$\ln w_{i}=\beta M_{i}+\alpha r_{i}+\delta K_{i}+\gamma N_{i}+\mu_{i}$

where $\ln w_{i}$ is the $\log$ of annual income for household $i$. $K$ is a vector of human capital and other demographic variables including education, experience and its square, the number of children in the household and dummy variables for race (2), gender, marital status (2), year of survey (4) and full-time status. $r_{i}$ is the average of the log housing value for individual $i$ 's county. As in typical hedonic wage models, local characteristics, $N$, are controlled for with a series of variables including local government per pupil expendi- 


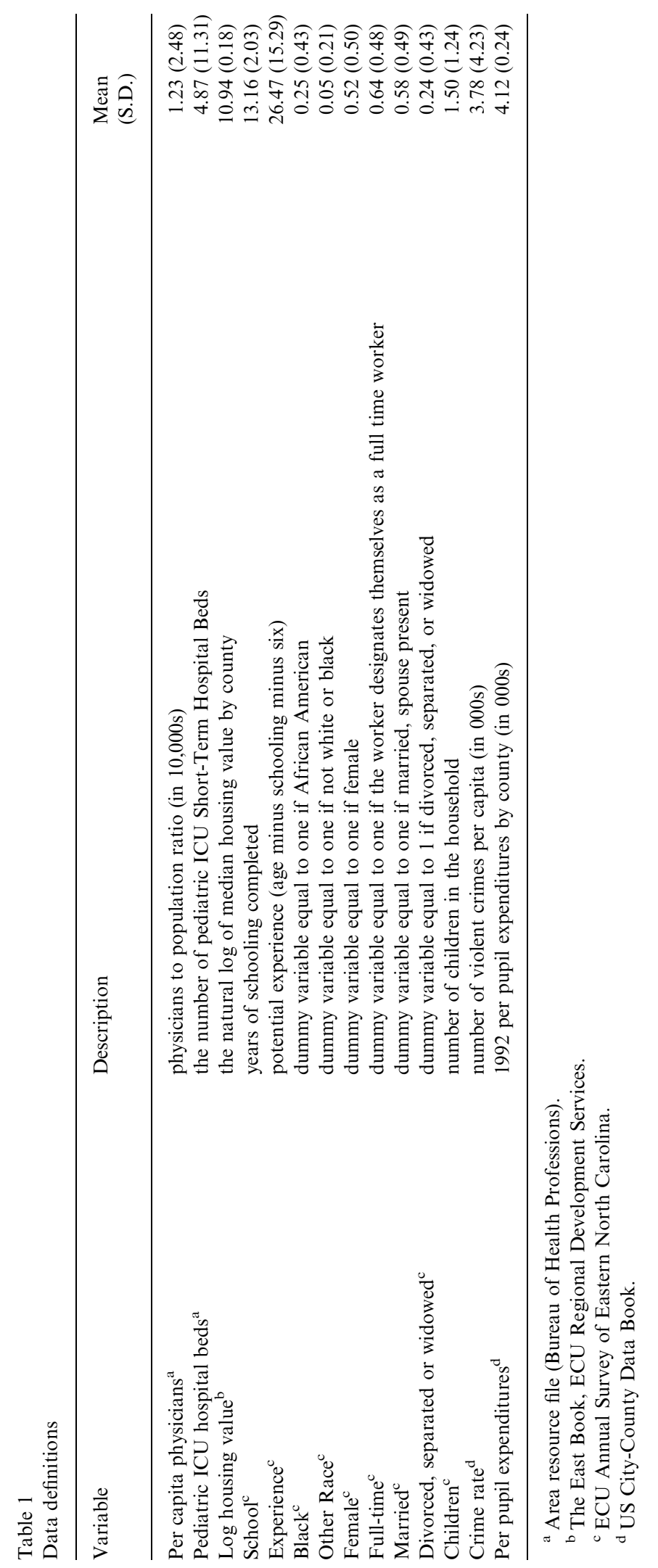


Table 2

Maximum likelihood estimates of earnings equations dependent variable: $\log$ of income group cutoffs ${ }^{\mathrm{a}}$

\begin{tabular}{|c|c|c|}
\hline Variable & 1 & 2 \\
\hline Constant & $-6.551(0.637)$ & $-7.551(0.743)$ \\
\hline Per capita physicians & $0.007(0.010)$ & $0.014(0.013)$ \\
\hline Pediatric ICU hospital beds & $0.002(0.002)$ & $-0.003(0.003)$ \\
\hline Underserved county & - & $-0.063^{*}(0.030)$ \\
\hline Underserved $\times$ physpop & - & $-0.123^{*}(0.045)$ \\
\hline Underserved $\times$ PICU Beds & - & $0.024 *(0.009)$ \\
\hline Log(housing value) & $0.174^{*}(0.054)$ & $0.087(0.066)$ \\
\hline School & $0.115^{*}(0.005)$ & $0.114^{*}(0.005)$ \\
\hline Experience & $0.021^{*}(0.002)$ & $0.021^{*}(0.002)$ \\
\hline Experience $^{2} / 100$ & $-0.039^{*}(0.004)$ & $-0.038^{*}(0.004)$ \\
\hline Black & $-0.291^{*}(0.023)$ & $-0.294 *(0.023)$ \\
\hline Other Race & $-0.129^{*}(0.044)$ & $-0.127^{*}(0.045)$ \\
\hline Female & $-0.071^{*}(0.019)$ & $-0.072^{*}(0.019)$ \\
\hline Married & $0.434^{*}(0.028)$ & $0.439 *(0.028)$ \\
\hline Divorced, separated or widowed & $-0.157^{*}(0.031)$ & $-0.156^{*}(0.031)$ \\
\hline Children & $0.039^{*}(0.008)$ & $0.040^{*}(0.008)$ \\
\hline Work full-time & $0.178^{*}(0.020)$ & $0.176^{*}(0.020)$ \\
\hline Crime rate & $-0.008(0.006)$ & $0.014(0.009)$ \\
\hline Per pupil expenditures & $-0.055(0.042)$ & $-0.070(0.044)$ \\
\hline 1992 & $-0.109^{*}(0.030)$ & $-0.107^{*}(0.030)$ \\
\hline 1993 & $-0.105^{*}(0.030)$ & $-0.103^{*}(0.030)$ \\
\hline 1994 & $-0.059^{*}(0.030)$ & $-0.058^{*}(0.030)$ \\
\hline 1995 & $0.000(0.029)$ & $0.000(0.029)$ \\
\hline Sample size & 3369 & 3369 \\
\hline Sigma & $0.509(0.007)$ & $0.508(0.007)$ \\
\hline Log-likelihood & -5730.052 & -5719.09 \\
\hline$\chi^{2}$ for joint significance of physicians and beds & 1.154 & $23.976^{*}$ \\
\hline
\end{tabular}

${ }^{\text {a }}$ Results are maximum likelihood estimates of the grouped data model where the dependent variable is the log of the income group cutoffs. Standard errors in parentheses. ${ }^{*}$ indicates significance at the $5 \%$ level.

ture and the rate of violent crime. Medical care amenities $(M)$ potentially include such variables as hospital beds, the per capita number of physicians and availability of specialty services ${ }^{4}$. Finally, $\mu$ is a wellbehaved error term ${ }^{5}$.

The wage-amenity model can be used to estimate non-market values for unpriced amenities. In this paper we assume a log-linear functional form of the model to be consistent with human capital theory (Mincer, 1974; Becker, 1993). The coefficient estimates, therefore, can be interpreted as log wage differentials, or approximate percentage differentials ${ }^{6}$. The focus of

\footnotetext{
${ }^{4}$ Our final specification of Eq. (6) includes per capita physicians and the number of pediatric intensive care beds in the county.

${ }^{5}$ We also included environmental amenity variables such as the natural $\log$ of pounds of hazardous waste generated by county or distance to the nearest major beach. None of these variables, however, were significantly different from zero in any of the model specifications.

${ }^{6}$ The coefficients are converted to percentage changes by the formula $\left(\mathrm{e}^{\beta}-1\right) \times 100$, where $\beta$ is the coefficient estimate.
}

this paper will be on the coefficient vector $\beta$, which will indicate the effect of various health care amenities on household income.

\section{The data}

The household level data are from 1991 through 1995 annual telephone surveys of eastern North Carolina households. The surveys used a random digit dialing sampling scheme with response rates of at least $70 \%$ in each year. Our data do not contain information on hours worked or hourly wages, rather the interviewer asks individuals to place themselves in one of eight income categories. The income categories (in 1995 dollars) are: less than $\$ 10,000(10.5 \%$ of the sample); between $\$ 10,001$ and $15,000(12.1 \%$ of the sample); between $\$ 15,001$ and $20,000(12.6 \%)$; between $\$ 20,001$ and $25,000(11.4 \%)$; between $\$ 25,001$ and $30,000(11.2 \%)$; between $\$ 30,001$ and $50,000(25.1 \%)$; between $\$ 50,001$ and $75,000(12.3 \%)$; and greater than $\$ 75,000$ (4.8\%). We omit those who did not list working as their primary activity, so that those who are 
enrolled in school and working or who are not in the labor force are deleted from the sample. The sample yields observations on 3369 households in the 41 counties that make up eastern North Carolina ${ }^{7}$.

Table 1 provides variable descriptions and means of all variables used in the final wage-amenity models. On average there are 1.23 physicians per 10,000 individuals in the counties and there are almost 5 pediatric ICU beds in each county. About $30 \%$ of the sample are non-white and almost $60 \%$ are currently married.

\section{Estimation results}

Since the income data is reported only by large categories, ordinary least squares regression estimates, employing the midpoints of the categories, will be biased (Stewart, 1983). Therefore, we use the maximum likelihood interval estimates from the GROUPED data command in LIMDEP (Greene, 1995) to obtain unbiased coefficient estimates. Table 2 displays the maximum likelihood estimates. Although the main focus of the paper is the impact of medical care inputs on earnings, the effect of the other independent variables are of interest. Schooling and experience are important determinants of earnings as these are the main measures of human capital in our model. Each year of schooling adds about $12 \%$ to family income. As is typical for an earnings equation, experience increases earnings at a decreasing rate. After controlling for other measurable characteristics, blacks and females earn substantially less than white males (about 25 and $7 \%$ respectively) ${ }^{8}$. This is a larger wage difference than obtained from most studies examining the impact of race on the entire labor market (Hirsch and Macpherson, 1994). Higher earnings are associated with marriage consistent with previous literature, however, single workers are estimated to earn more than previously married individuals. This later result is contrary to previous literature (Korenmen and Neumark, 1991). There is also a wage differential for the presence of children, which may capture investments in human capital. Earnings are highest in 1991 (the omitted year) and are lowest in 1992 and 1993, but return to their 1991 levels by 1995 .

The wage-amenity specification in column 1 of Table 2 includes the per capita physician ratio and the number of pediatric intensive care unit beds. With the other variables held constant, both of these medical care inputs have an insignificant effect on earnings.

\footnotetext{
${ }^{7}$ Table 4 provides a list of these counties as well as descriptive information about each county.

${ }^{8}$ The $\log$ point difference of -0.291 is converted into a percentage difference by $\left(\mathrm{e}^{-0.291}-1\right) \times 100=-25.2 \%$.
}

The critical value for the $\chi^{2}$ test of joint significance for these two variables is 1.154 which implies that they are not jointly significant.

These findings imply that the health care inputs are not an important determinant of earnings. An alternative, though unlikely, explanation is that the productivity effect just offsets the amenity effect of health care inputs and thus the net effect is zero. Since eastern North Carolina has been singled out as a 'medically underserved' area of the county, this finding is significant. Before we conclude that health care inputs do not matter, however, we explore the underserved area effects a little more closely. Not all counties in this area are medically underserved. A number of counties have been designated as Health Professional Shortage Areas (HPSAs). A ratio of one primary care physician per 3500 people is used to designate a HPSA (Project East, 1993). Appendix Table 4 indicates that 18 of the 41 counties in the region have been designated as medically underserved.

Column 2 of Table 2 displays the results of including a dummy variable for a medically underserved county and the effects of interacting this variable with the health care inputs. The results show that while there appears to be no overall effect of health care inputs on earnings, there is a rather large effect in counties that have been deemed medically underserved. The critical value for the $\chi^{2}$ test of joint significance for the medical inputs and the two interaction terms is 23.98 , which is highly significant. Workers in counties that are underserved receive earnings about $6 \%$ lower than workers in other counties, all things equal. This is likely capturing the relatively worse economic conditions in these counties (note that the coefficient on the log housing value decreases and is no longer significant).

The coefficients on the interaction terms indicate that medical inputs are important determinants of earnings in underserved areas. The effect of physicians is significantly negative in underserved areas suggesting that the amenity component of physicians overwhelms any productivity effect. Each additional physician per 10,000 individuals in the county decreases earnings by about $10.3 \%(0.014-0.123=-0.109 \log$ points $)$, holding all other variables constant. Pediatric ICU beds, on the other hand, are estimated to be a productivity enhancing characteristic. Each additional pediatric ICU bed is estimated to increase earnings by about $2.1 \%(-0.003+0.024=0.021 \log$ points $)$. A priori, one might expect the presence of a pediatric ICU to appear as only an amenity since it is unlikely that this medical service could directly affect worker productivity. It may be, however, that this variable rather than indicating the direct effect of a pediatric ICU is capturing other characteristics of a hospital. That is, for example, hospitals with higher quality facilities or doctors is likely to be considered a productivity-enhancing 
Table 3

Separate effects by race ${ }^{a}$

\begin{tabular}{lrr}
\hline Variable & White & Nonwhite \\
\hline Per capita physicians & $0.007(0.016)$ & $0.050^{*}(0.027)$ \\
Pediatric ICU hospital beds & $-0.005(0.004)$ & $0.006(0.006)$ \\
Underserved county & $-0.054(0.037)$ & $-0.061(0.057)$ \\
Underserved $\times$ physpop & $-0.124^{*}(0.052)$ & $-0.052(0.114)$ \\
Underserved $\times$ PICU beds & $0.025^{*}(0.010)$ & $-0.004(0.024)$ \\
\hline
\end{tabular}

\footnotetext{
${ }^{a}$ Shown are the coefficients on health inputs estimated separately by race. Other than the variables shown, other variables included in the regression are the same as in Table 2 with the exception of the race dummies. ${ }^{*}$ indicates the coefficient is significant at the $5 \%$ level.
}

characteristic and these hospitals also are likely to provide pediatric ICU care.

A potential problem with our model specification is that doctors and hospital beds may be endogenous. Doctors and hospitals may be attracted to areas where wages are higher and thus treating them as exogenous may lead to biased estimates of the effects of these variables on earnings. We test for the endogeneity of physicians and beds using the technique of Blundell and Smith (1986) adapted to the interval regression and find no evidence for endogeneity. We first estimate a county level model for physician and bed location. This model is identified using county-level characteristics. These models have $\mathrm{R}^{2}$ values greater than 0.70 for both models. We then include the residuals from these models in the individual income equation. A significant coefficient on this residual would lead one to conclude that there is evidence of endogeneity bias. The coefficients on the residuals are not significantly different from zero (asymptotic $t$-values $=0.86,0.23$ ). Thus, these results suggest that there is no evidence of endogeneity and estimating the Grouped data model including physicians and beds on the right-hand-side will not lead to biased coefficient estimates.

Wage-amenity models including other medical care inputs as alternative independent variables performed less well than the specification shown in Table 2. For example, including such variables as the number of primary care physicians, the number of emergency rooms, the presence of an open heart surgery unit, or a

\footnotetext{
${ }^{9}$ We also examined the possibility that the public good component of medical care may have diminished over the period due to the rise of managed care and lowered transportation costs. If large changes occurred over the period, we should find large differences between the early years of the sample and the later years. We estimated separate models for the years 1991-1992 and the years 1993-1995. We find that there is no evidence for change over the period. The coefficient estimates are virtually identical for both sub-periods.
}

dummy variable equal to one if the county had at least one open heart unit, pediatric intensive care unit, or angioplasty unit were generally insignificant in the earnings equations. This suggests that while previous studies examining the hedonic value of medical care inputs may not have had access to detailed health care input variables, it appears that their results are not biased by these omissions? .

Table 3 displays specifications run separately for whites and nonwhites. There are surprisingly large differences in the effects of medical care inputs between the white and nonwhite population. The results for whites are similar to those for the population. Separate estimates for nonwhites indicate that while there is not a distinct underserved county effect, the effect of physicians is positive and significant. Each additional physician per 10,000 individuals in the county increases nonwhite family income by about $5 \%$, while the effect for white families is negative and only appears in underserved counties. Also, according to the likelihood-ratio test, the vector of coefficients for whites is significantly different from the coefficient vector for nonwhites $\left(\chi^{2}=111.91[15\right.$ d.f.] $)$.

While the small sample size for nonwhites $(n=1000)$ make firm conclusions difficult, these findings suggest that medical inputs have a substantially larger productivity enhancing effect for nonwhites than for whites. This finding is consistent with empirical findings on the production of health which concludes that the marginal product of medical care inputs on individual health are typically much stronger for blacks than for whites (Corman et al., 1987; Hadley 1988; Folland et al., 1997). Since the marginal product of medical care is higher for blacks than whites, it follows that the marginal impact of medical care inputs on earnings will be higher for blacks as well. If this were the case, however, one may expect that this effect would be stronger in underserved areas. We do not see this. An alternative explanation could be that the productivity effects are similar, but whites place a higher value on medical care amenities than non-whites. Whatever the explanation, it is clear from these results that there are distinct differences in the way medical inputs affect white and nonwhite individuals.

\section{Conclusions}

This paper is concerned with the effects of medical care inputs on primarily rural household incomes. Because of the quasi-public good nature of medical care inputs, it is difficult to measure the full price or value of these inputs. The approach taken here is to estimate a hedonic wage function, which relates the earnings of workers to a particular labor market or local area characteristics. Medical care inputs are 
found to have an insignificant effect on earnings for the region as a whole, but there are significant effects in counties that have been designated as medically underserved. The physician to population ratio in medically underserved counties is found to be a utility enhancing characteristic. Each physician per 10,000 individuals in the population decreases earnings by about $12 \%$. The number of pediatric intensive care beds, however, appears as a small productivity-enhancing characteristic. This variable is likely capturing an overall prestige value of the hospital. We also find evidence that the productivity component of health care inputs is stronger for blacks than for whites.

Our results are suggestive for a number of reasons. First, our study is the first to include more highly detailed controls for medical care inputs, allowing us to probe deeper into the effect of medical care inputs on incomes. It appears that previous studies including only limited health care inputs are not seriously biased. Second, our study is the first to focus on a rural area in which policy makers have been concerned with the underprovision of medical services ${ }^{10}$. It appears that there are distinct differences between the effects of medical inputs in areas that are deemed medically underserved. The results suggest that these services are highly valued by firms and workers in the region and have policy implications for the economic development of poor, rural regions. For example, if firms value medical care inputs when they make location decisions and poor areas are underserved in terms of inputs, this puts a binding constraint on the economic development of the poor region.

A common finding in the health production literature is that while the marginal product of health care is relatively low for the population as a whole, it is significantly larger for certain subgroups (Hadley, 1982, 1988). Our findings are consistent with this conclusion. Previous studies examining the impact of physician inputs on wages typically find that they are negatively correlated (Gyourko and Tracy, 1991). Our finding that there is a positive wage effect of physicians for blacks suggests that there is a strong productivity effect for this group of workers, consistent with the marginal product of health care being relatively large for this group of workers.

These results also suggest avenues for further research. Most wage-amenity models employ urban data while our data is for a rural region. Since there are significant concerns about the rural location decisions for physicians, models that include both urban and rural households and the definitions of medically underserved regions may provide insights about the

\footnotetext{
${ }^{10}$ See, for example, Project EAST Profiles, a publication of East Carolina University, September 1993.
}

Table 4

Counties included in survey ${ }^{\mathrm{a}}$

\begin{tabular}{|c|c|c|c|}
\hline County & 1990 Population & Observations & Underserved \\
\hline Beaufort & 42,283 & 76 & no \\
\hline Bertie & 20,388 & 27 & yes \\
\hline Bladen & 28,663 & 45 & yes \\
\hline Brunswick & 50,985 & 55 & no \\
\hline Camden & 5904 & 14 & no \\
\hline Carteret & 52,553 & 85 & no \\
\hline Chowan & 13,506 & 27 & no \\
\hline Columbus & 49,587 & 79 & yes \\
\hline Craven & 81,613 & 158 & no \\
\hline Cumberland & 274,713 & 390 & yes \\
\hline Currituck & 13,736 & 22 & no \\
\hline Dare & 22,746 & 33 & no \\
\hline Duplin & 39,995 & 80 & yes \\
\hline Edgecombe & 56,692 & 117 & yes \\
\hline Gates & 9305 & 16 & yes \\
\hline Greene & 15,385 & 45 & yes \\
\hline Halifax & 55,516 & 83 & no \\
\hline Harnett & 67,833 & 116 & no \\
\hline Hertford & 22,523 & 34 & no \\
\hline Hoke & 22,856 & 41 & yes \\
\hline Hyde & 5411 & 5 & yes \\
\hline Johnston & 81,306 & 142 & no \\
\hline Jones & 9414 & 10 & yes \\
\hline Lenoir & 57,274 & 103 & no \\
\hline Martin & 25,078 & 45 & yes \\
\hline Nash & 76,677 & 109 & no \\
\hline New Hanover & 120,284 & 217 & no \\
\hline Northampton & 20,798 & 31 & yes \\
\hline Onslow & 149,838 & 176 & yes \\
\hline Pamlico & 11,368 & 20 & no \\
\hline Pasquotank & 31,298 & 50 & no \\
\hline Pender & 28,855 & 59 & yes \\
\hline Perquimans & 10,447 & 18 & no \\
\hline Pitt & 108,480 & 229 & no \\
\hline Robeson & 105,170 & 165 & yes \\
\hline Sampson & 47,297 & 81 & no \\
\hline Scotland & 33,763 & 42 & no \\
\hline Tyrrell & 3856 & 3 & yes \\
\hline Washington & 13,997 & 27 & yes \\
\hline Wayne & 104,666 & 181 & no \\
\hline Wilson & 66,061 & 113 & no \\
\hline Total & $2,060,110$ & 3369 & \\
\hline
\end{tabular}

${ }^{a}$ Populations are from the 1990 Census of Population and Housing. A county is underserved if there are fewer than one primary care physician per 3500 individuals.

migration of households and firms in pursuit of physicians. Future wage-amenity models that include medical care inputs could also include measures of environmental health amenities in order to test for the substitutability of averting behavior and medical care. Finally, much research has determined that the valuation of amenities is determined in both labor and land markets. Our wage-amenity models include a proxy 
variable for the housing market. Future research should employ a multi-market approach, if data allows, to determine the full effect of medical care inputs on quality of life.

\section{References}

Becker, G.S., 1993. Human Capital, third ed. University of Chicago Press, Chicago, IL (original ed., 1964).

Blundell, R., Smith, R., 1986. An exogeneity test for a simultaneous equation tobit model with an application to labor supply. Econometrica 54 (3), 679-685.

Blomquist, G.C., Berger, M.C., Hoehn, J.P., 1988. New estimates of quality of life in urban areas. American Economic Review 78, 89-107.

Clark, D.E., Kahn, J.R., 1989. The two-stage hedonic wage approach: a methodology for the valuation of environmental amenities. Journal of Environmental Economics and Management 16, 106-120.

Corman, H., Joyce, T.J., Grossman, M., 1987. Birth outcome production function in the United States. Journal of Health Economics 4, 213-236.

Dalenberg, D., Partridge, M.D., 1997. Public infrastructure and wages: public capital's role as a productive input and household amenity. Land Economics 73, 268-284.

Folland, S., Goodman, A.C., Stano, M., 1997. The Economics of Health and Health Care. Prentice Hall, Upper Saddle River, NJ.

Goetz, S.J., Debertin, D.L., 1996. Rural-urban locational choices of medical doctors: a county level analysis. Review of Agricultural Economics 18, 547-563.

Greene, W.H., 1995. LIMDEP: User's Manual, Version 7.0.
Gyourko, J., Tracy, J., 1991. The structure of local public finance and the quality of life. Journal of Political Economy 99, 774-806.

Hadley, J., 1988. Medicare spending and mortality rates of the elderly. Inquiry 25, 485-493.

Hadley, J., 1982. More Medical Care, Better Health? Urban Institute, Washington, DC.

Hirsch, B.T., Macpherson D.A., 1994. Wages, Racial Composition and Quality Sorting in Labor Markets. Institute for Research on Poverty Discussion Paper DP1038-94.

Korenmen, S., Neumark, D., 1991. Does marriage really make men more productive? The Journal of Human Resources 26, 282-307.

Lee M.L., Jones, L.W., 1993. The fundamentals of good medical care. Publication of the Committee on the Costs of Medical Care, University of Chicago.

Mincer, J., 1974. Schooling, Experience and Earnings. Columbia University Press.

Roback, J., 1982. Wages, rents and the quality of life. Journal of Political Economy 90, 1257-1278.

Rosen, S., 1974. Hedonic prices and implicit markets: product differentiation in pure competition. Journal of Political Economy 82, 34-55.

Stewart, M.B., 1983. On least squares estimation when the dependent variable is grouped. Review of Economic Studies 8, 27-44.

Weisbrod, B.A., 1975. Towards a theory of the voluntary non-profit sector in a three-sector economy. In: Phelps, E.S. (Ed.), Altruism, Morality and Economic Theory. Russell Sage Foundation, New York.

Weisbrod, B.A., 1988. The Nonprofit Economy. Harvard, Cambridge, MA. 